\title{
Treatment outcomes from community-based drug resistant tuberculosis treatment programs: a systematic review and meta-analysis
}

\author{
Pamela Weiss ${ }^{1}$, Wenjia Chen ${ }^{2}$, Victoria J Cook ${ }^{3,4}$ and James C Johnston ${ }^{3,4^{*}}$
}

\begin{abstract}
Background: There is increasing evidence that community-based treatment of drug resistant tuberculosis (DRTB) is a feasible and cost-effective alternative to centralized, hospital-based care. Although several large programs have reported favourable outcomes from community-based treatment, to date there has been no systematic assessment of community-based DRTB treatment program outcomes. The objective of this study was to synthesize available evidence on treatment outcomes from community based multi-drug resistant (MDRTB) and extensively drug resistant tuberculosis (XDRTB) treatment programs.
\end{abstract}

Methods: We performed a systematic review and meta-analysis of the published literature to examine treatment outcomes from community-based MDRTB and XDRTB treatment programs. Studies reporting outcomes from programs using community-based treatment strategies and reporting outcomes consistent with WHO guidelines were included for analysis. Treatment outcomes, including treatment success, default, failure, and death were pooled for analysis. Meta-regression was performed to examine for associations between treatment outcomes and program or patient factors.

Results: Overall 10 studies reporting outcomes on 1288 DRTB patients were included for analysis. Of this population, 65\% [95\% Cl 59-71\%] of patients had a successful outcome, 15\% [95\% Cl 12-19\%] defaulted, 13\% [95\% Cl 9-18\%] died, and 6\% [95\% Cl 3-11\%] failed treatment for a total of 35\% [95\% Cl 29-41\%] with unsuccessful treatment outcome. Meta-regression failed to identify any factors associated with treatment success, including study year, age of participants, HIV prevalence, XDRTB prevalence, treatment regimen, directly observed therapy (DOT) location or DOT provider.

Conclusions: Outcomes of community-based MDRTB and XDRTB treatment outcomes appear similar to overall treatment outcomes published in three systematic reviews on MDRTB therapy. Work is needed to delineate program characteristics associated with improved treatment outcomes.

Keywords: Tuberculosis, Multidrug-resistant, Treatment, Community based

\section{Background}

Drug resistant tuberculosis (DRTB) is a global health concern that undermines recent successes in tuberculosis (TB) control [1]. DRTB includes both multidrug-resistant (MDR) and extensively drug-resistant (XDR) TB; MDRTB strains are resistant to the two most-effective first-line anti-TB drugs, while XDRTB is resistant to four highly

\footnotetext{
* Correspondence: james.johnston@bccdc.ca

${ }^{3}$ Division of Respirology, University of British Columbia, Vancouver, Canada

${ }^{4}$ The British Columbia Center for Disease Control, 655 West 12th Avenue,

Vancouver, BC V5Z4R4, Canada

Full list of author information is available at the end of the article
}

effective anti-TB drugs [2]. Worldwide there are approximately 650,000 cases of MDRTB of which $10 \%$ are XDRTB [3,4]. Without significant scale-up in diagnostic and treatment capacity for DRTB, MDRTB and XDRTB could become the dominant forms of TB worldwide [1].

Treatment of MDRTB and XDRTB requires secondline anti-TB drugs that are more costly, less efficacious and more toxic than first-line drugs [4,5], and require $\geq 20$ months of medical therapy [6]. Treatment is typically delivered using the WHO DOTS-Plus model and traditionally involves prolonged inpatient treatment

\section{Biomed Central}

(c) 2014 Weiss et al.; licensee BioMed Central Ltd. This is an Open Access article distributed under the terms of the Creative Commons Attribution License (http://creativecommons.org/licenses/by/2.0), which permits unrestricted use, distribution, and reproduction in any medium, provided the original work is properly credited. 
that enables enhanced monitoring of adverse drug reactions, ensures adherence, and may prevent spread within the community $[7,8]$. Unfortunately, resource limitations often force patients to wait months for inpatient therapy, during which time they can spread to other people in their community. Inpatient therapy also increases the risk of nosocomial transmission, particularly in low-resource settings.

To address these challenges, many DRTB treatment programs have incorporated community participation in the DRTB treatment. Community-based directly observed therapy (cb-DOTS) programs are low-cost treatment programs that utilize family members, neighbours, coworkers, local health care workers (HCWs) or former patients to directly observe treatment rather than requiring hospitalizations or frequent visits to a health care facility. For drug-susceptible TB, cb-DOTS appears comparable or better than hospital-based approaches [9-11]. Many research groups have examined treatment outcomes of community-based DRTB treatment models and report good results, however to date no systematic evaluation of cb-DRTB programs has been reported in the literature. Our objective was to synthesize available evidence on treatment outcomes from community based multi-drug resistant (MDRTB) and extensively drug resistant tuberculosis (XDRTB) treatment programs.

We performed a systematic review and meta-analysis to investigate treatment outcomes in community-based MDRTB and XDRTB treatment programs. For the purpose of this study, community-based refers to treatment that occurs on an outpatient basis, and includes participation by community members in treatment delivery. Treatment outcomes were examined and pooled for analysis. Program and patient characteristics were also analyzed to determine the effect these variables had on treatment success.

\section{Methods}

The present review have been reported according to the preferred reporting items for systematic reviews and meta-analyses (PRISMA) (Additional file 1).

\section{Search strategy}

A methodical strategy was used to identify relevant publications. Our search strategy was modeled after Johnston et al. [12] and Orenstein et al. [13] with slight modification. The search was limited to English language publications in the EMBASE, MEDLINE, International Pharmaceutical Abstracts and BIOSIS databases and the Web of Science that were published between January 1990 and August 2012. Keyword searches were conducted on both titles and abstracts to identify relevant publications using combinations of the keywords "MDR", "XDR", "drug resistant", "drug-resistant", "multidrug", "multi-drug", "extensively", “TB", "tuberculosis", "directly observed", "DOTS", "DOTS-Plus", "cb-DOTS", "treatment", "community", "outpatient", "public participation", "community-based", "decentralized", "home-based", "ambulatory", "clinic", "community health worker", and "CHW". A search of EBM reviews was also conducted to determine existing systematic reviews on this topic. This included Database of Abstracts of Reviews and Effects, Cochrane Central Register of Controlled Trials and Cochrane Database of Systematic Reviews. Citations were all thoroughly reviewed and it was determined that no systematic reviews were published on this subject. Online archives of several journals were also methodically searched manually from January 1990 (when available). Journals searched included American Journal of Respiratory and Critical Care Medicine, Clinical Infectious Disease, Chest, International Journal of Tuberculosis and Lung Disease, and Journal of Infectious Disease. Bibliographic searches of identified articles were conducted to identify other relevant studies.

\section{Selection of studies}

Relevant articles were reviewed and examined for eligibility beginning with the abstract and followed by full text review. The following inclusion criteria were applied: original study; published in English after January 1990; reported treatment outcomes on patients with culture-confirmed MDRTB or XDRTB; utilized directly observed treatment on an outpatient basis; employed community-based treatment strategies; reported treatment outcomes that would allow for comparison with other studies. Studies were excluded if they utilized only surgical interventions, reported only preliminary outcomes, routinely hospitalized patients for $\geq$ six months, or did not report data in a format enabling extraction.

\section{Methodological assessment}

Two authors (P.W. and J.J.) independently assessed the methodological quality of the selected studies considered in the current review. Randomized controlled-trials, prospective cohorts, retrospective cohorts or consecutive case control studies were assessed. Publications included in this analysis reported treatment outcomes for $\geq$ five patients, reported results on at least $50 \%$ of patients, reported general demographic information on patients, and included community-based treatment $\geq$ six months in duration and total treatment duration of $\geq 18$ months. In the case of duplicate data, the publication with the more detailed reports on treatment outcomes was included for meta-analysis. Studies were selected by one author (P.W.), with selected studies reviewed for inclusion/exclusion by two authors (P.W, J.J.). 


\section{Treatment outcome definitions}

We used treatment outcome measures defined by Laserson et al. and the WHO [5,14]. Patients that met the criteria for cure or treatment completed were classified as having successful treatment outcomes. Patients that met criteria for death, treatment default, treatment failure or transfer out were classified as having unsuccessful treatment outcomes. For data analysis, patients whose results were not available or patients that met transfer out criteria were placed in the treatment default category.

\section{Study characteristics}

The association between treatment success and several study characteristics was examined among several subgroups. Factors examined included study year (enrollment started before 2002 versus after 2002), patient age ( $>14$ years versus $\leq 14$ ), HIV prevalence (in the cohort described) (0-2\%; >2\%), XDRTB infection ( $0 \%$; >0\%), treatment regimen (individualized; standardized), DOT location (home-based; clinic/PHC-based) and DOT provider (CHWs/HCWs only; included family/friends).

\section{Data analysis}

Data extraction was performed by one author (P.M.) and cross-checked by a second author (J.J.). Data was analyzed using Microsoft Excel (version 14.1.0) and StatsDirect (version $2 \cdot 7 \cdot 9$ ) and STATA/IC v12 0 . Treatment outcome data (successful, default, death and failure) across all studies were pooled to measure overall treatment outcomes associated with community-based treatment. The Heterogeneity between these studies was assessed with by calculating $\mathrm{I}^{2}$ test. A calculated value of $\mathrm{I}^{2}>50 \%$ indicated substantial heterogeneity. For pooling of these results, we used a more conservative random-effect model. An Egger test was used to assess for publication bias, and funnel plots were created.

To examine sources of heterogeneity, a random-effects meta-regression was performed. The dependent variable was logit-transformed DRTB treatment success (ES). All 10 studies were included in this analysis. For $\mathrm{ES}=0$ or 1 , to avoid generating missing data, a small adjustment term $(2 \mathrm{n})^{-1}$ was applied to the logit-transformation [15]. Standard errors were adjusted in accordance. This analysis was based on a significance level at $\mathrm{p}=0 \cdot 05$. Predictors were examined using univariate meta-regression models.

\section{Results}

Figure 1 shows the study selection process. The initial database search yielded 584 articles, while manual search and bibliographic search yielded 33 additional articles. Of these articles, 103 were retained for full text review; 88 studies were excluded for various reasons, leaving 10 articles for analysis (Figure 1) [16-25]. Overall the dates of enrollment for studies ranged from 1996-2011 and examined populations in six different countries (Table 1). Eight studies were retrospective and two were prospective.

\section{Study heterogeneity}

There was a high degree of heterogeneity between studies. This was not unexpected, as each study differed in terms of population characteristics and treatment model. Studies involved a mean 129 participants with a broad range of sample sizes (5-651) (Table 1). Two studies only included children under $\leq 15$ years $[19,25]$. Two studies reported and included patients infected with XDRTB, with a mean of $4 \cdot 4 \%(1-7)$. Four studies reported and included patients co-infected with HIV, with a mean of $28 \cdot 2 \%(1-60)$. Of the eight studies that reported on previous TB therapy, $94 \cdot 3 \%(65-100)$ of patients received previous treatment. Eight studies reported on retrospective cohorts, while two studies reported on prospective cohorts.

In terms of treatment models, six studies utilized an individualized regimen and four studies utilized a standardized regimen (Table 2). Treatment duration was expressed in different ways and varied between studies. All studies except two reported the DOTS location; these two studies described outpatient treatment. The other studies involved treatment at local health centers or decentralized clinics, local hospitals or in patient homes. The DOTS provider was reported in all studies and consisted of CHWs, HCWs, local nurses, friends, neighbours or household members. Some studies reported additional community involvement in the form of community education and support programs, the nomination of treatment support individuals and community teams that tracked patients and did home visits if any treatments were missed.

\section{Treatment outcomes}

Overall, the 10 studies examined the treatment outcomes of 1288 DRTB patients (Table 3; Figure 2). Of this population, 65\% [95\% CI 59-71\%] had a successful outcome (Figure 2). A total of 15\% [95\% CI 12-19\%] of patients defaulted, $13 \%$ [95\% CI 9-18\%] of patients died, and $6 \%$ [95\% CI 3-11\%] failed treatment for a total of 35\% [95\% CI 29-41\%] with an unsuccessful treatment outcome. Heterogeneity between studies was high $\left(\mathrm{I}^{2}>50 \%\right)$ for all treatment outcomes except default. All pooled treatment outcome results were statistically significant $(p<0 \cdot 05)$. Based on the funnel plot, there was no evidence of publication bias (Additional file 2) (Egger test $\mathrm{p}=0 \cdot 69$ ).

\section{Subgroup treatment success}

Treatment success among study subgroups was pooled and analyzed (Table 4). The univariate meta-regression analysis was performed to explain the source of heterogeneity. Treatment success did not differ significantly 


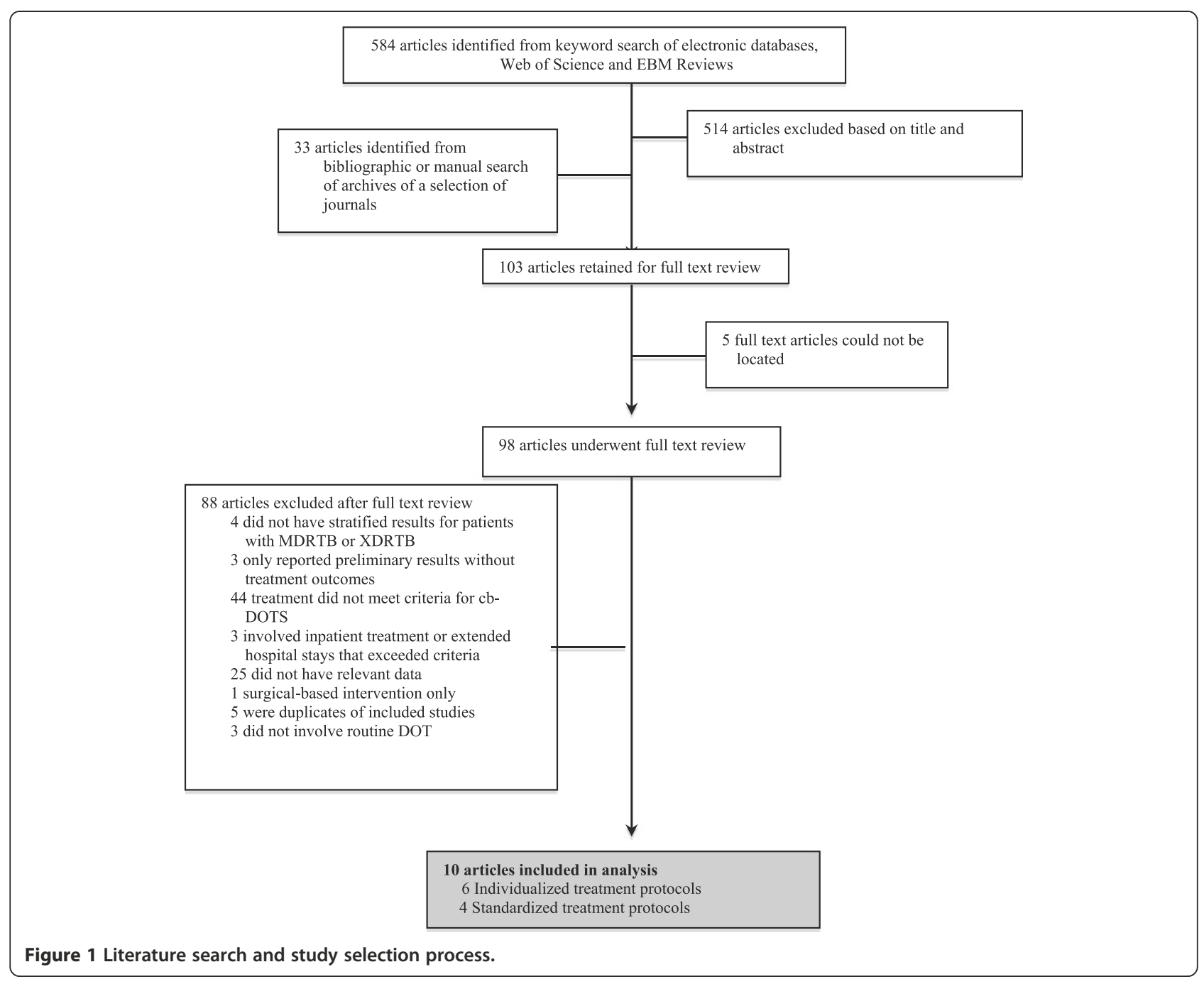

Table 1 Baseline characteristics of the included studies

\begin{tabular}{|c|c|c|c|c|c|c|c|c|}
\hline Study & Location & Date & Study type* & Sample size & XDR (\%) & HIV (\%) & Previous therapy (\%) & Mean resistance \\
\hline Drobac et al [19] & Peru & 1999-2003 & $\mathrm{RC}$ & 27 & - & - & - & - \\
\hline Joseph et al [17] & India & $2006-2007$ & PC & 38 & 0 & 0 & 100 & $3 \cdot 6$ \\
\hline Malla et al [22] & Nepal & $2005-2006$ & $\mathrm{RC}$ & 175 & - & - & 93 & $3 \cdot 7$ \\
\hline Mitnick et al. [20] & Peru & 1996-1999 & $\mathrm{RC}$ & 75 & - & $1 \cdot 3$ & 100 & Median 6 \\
\hline Mitnick et al. [21] & Peru & 1999-2002 & $\mathrm{RC}$ & 651 & $7 \cdot 4$ & $1 \cdot 4$ & 65 & $5 \cdot 3,8 \cdot 4$ \\
\hline Oyieng'o et al. [24] & Kenya & $2008-2010$ & $\mathrm{RC}$ & 8 & 0 & 50 & 100 & $3 \cdot 1$ \\
\hline Satti et al. [25] & Lesotho & 2007-2011 & $\mathrm{RC}$ & 5 & 0 & 60 & - & 2.8 \\
\hline Singla et al. [16] & India & $2002-2006$ & $\mathrm{RC}$ & 126 & - & 0 & 100 & 3 \\
\hline Thomas et al. [18] & India & 1999-2003 & PC & 66 & $1 \cdot 5$ & - & 100 & $3 \cdot 4$ \\
\hline Tupasi et al. [23] & Philippines & 1999-2002 & $\mathrm{RC}$ & 117 & - & - & 96 & - \\
\hline
\end{tabular}

${ }^{*} \mathrm{RC}=$ retrospective cohort; $\mathrm{PC}=$ prospective cohort. 
Table 2 Description of the treatment in the included studies

\begin{tabular}{|c|c|c|c|c|c|c|}
\hline Study & Model* & $\begin{array}{l}\text { Treatment } \\
\text { duration } \\
\text { (months) }\end{array}$ & $\begin{array}{l}\text { Drugs in } \\
\text { regimen }\end{array}$ & DOTS location & DOTS provider & $\begin{array}{l}\text { Additional } \\
\text { community } \\
\text { involvement }\end{array}$ \\
\hline Drobac et al. [19] & I & $18-24$ & $\mathrm{n} / \mathrm{a}$ & Local health centre & CHWs, nurses & $\begin{array}{l}\text { CHWs provided doses } \\
\text { outside centre hours }\end{array}$ \\
\hline Joseph et al. [17] & S & $6-9,18$ & 6,4 & Local health centre & $\begin{array}{l}\text { HCWs, friends/ } \\
\text { neighbours }\end{array}$ & $\begin{array}{l}\text { Health education } \\
\text { provided for family }\end{array}$ \\
\hline Malla et al. [22] & S & $8-12,16-24$ & 5,4 & Decentralized clinics & Health workers & $\begin{array}{l}\text { Nominated treatment } \\
\text { support person required }\end{array}$ \\
\hline Mitnick et al. [20] & 1 & Median $23(0 \cdot 4-35 \cdot 9)$ & Median 6 (5-9) & Outpatient & CHWs, nurses & - \\
\hline Mitnick et al. [21] & 1 & $\geq 18$ & $\geq 5$ & Health centre or patient home & $\mathrm{CHWs}$ & Group therapy as needed \\
\hline Oyieng'o et al. [24] & S & $\geq 6,18$ & 5,4 & $\begin{array}{l}\text { Local health centre } \\
\text { or patient home }\end{array}$ & $\begin{array}{l}\text { Local nurse, HCW, } \\
\text { household member }\end{array}$ & $\begin{array}{l}\text { Household member } \\
\text { supervised evening dose }\end{array}$ \\
\hline Satti et al. [25] & 1 & $\geq 18$ & 6 & Outpatient & CHWs & $\begin{array}{l}\text { Community team } \\
\text { tracked patients and } \\
\text { provided support }\end{array}$ \\
\hline Singla et al. [16] & S & $6-9,18$ & 5,3 & $\begin{array}{l}\text { Peripheral health } \\
\text { centre or patient home }\end{array}$ & HCW, household member & $\begin{array}{l}\text { Household member } \\
\text { supervised evening dose }\end{array}$ \\
\hline Thomas et al. [18] & 1 & $\geq 18$ & $5, \geq 2$ & $\begin{array}{l}\text { Village health centres, } \\
\text { clinics or hospital }\end{array}$ & $\begin{array}{l}\text { Anganwadi workers, } \\
\text { village HCWs, } \\
\text { private practitioners }\end{array}$ & - \\
\hline Tupasi et al. [26] & 1 & $\geq 6, \geq 18$ & 5,4 & $\begin{array}{l}\text { Local health centre, } \\
\text { or patient home }\end{array}$ & HCWs & $\begin{array}{l}\text { Treatment partner } \\
\text { nominated by the patient }\end{array}$ \\
\hline
\end{tabular}

*I = Individualized, $\mathrm{S}=$ Standardized.

${ }^{\ddagger}$ Duration of intensive phase and continuation phase are separated by a comma. Otherwise duration represents length of treatment. ${ }^{\dagger} \mathrm{Number}$ of drugs in intensive and continuation regimens separated by a comma.

based on study year, age of participants, HIV prevalence, XDRTB prevalence, treatment regimen, DOTS location or DOT provider (Additional file 3).

\section{Discussion}

Over the past decade, evidence has amassed from treatment programs in low-income regions to demonstrate the feasibility, safety and cost-effectiveness of cb-DRTB therapy. Our findings provide further evidence to support this once controversial model of care. Overall, treatment success was $65 \%$ [95\% CI 59-71] in a population of MDRTB and XDRTB patients. The results from this study are comparable to outcomes reported in two previous meta-analyses of published MDRTB literature and one individual patient data meta-analysis (Figure 2) $[12,13,26]$. When compared with all treatment outcomes

Table 3 Outcomes at the end of treatment

\begin{tabular}{|c|c|c|c|c|c|}
\hline \multirow[t]{2}{*}{ Authors } & \multirow{2}{*}{$\begin{array}{l}\text { Sample } \\
\text { size }\end{array}$} & \multirow{2}{*}{$\begin{array}{l}\text { Successful } \\
\text { outcome (n) }\end{array}$} & \multicolumn{3}{|c|}{ Unsuccessful outcome } \\
\hline & & & Default (n) & Death (n) & Failure (n) \\
\hline Drobac et al. [19] & 27 & 21 & 5 & 1 & 0 \\
\hline Joseph et al. [17] & 38 & 25 & 5 & 3 & 5 \\
\hline Malla et al. [22] & 175 & 123 & 29 & 14 & 9 \\
\hline Mitnick et al. [20] & 75 & 55 & 14 & 5 & 1 \\
\hline Mitnick et al. [21] & 651 & 429 & 70 & 134 & 18 \\
\hline Oyieng'o et al. [24] & 8 & 6 & 0 & 2 & 0 \\
\hline Satti et al. [25] & 5 & 5 & 0 & 0 & 0 \\
\hline Singla et al. [16] & 126 & 76 & 22 & 24 & 4 \\
\hline Thomas et al. [18] & 66 & 25 & 16 & 8 & 17 \\
\hline Tupasi et al. [26] & 117 & 71 & 16 & 18 & 12 \\
\hline Summary & 129 & $65 \%$ & $15 \%$ & $13 \%$ & $6 \%$ \\
\hline $95 \% \mathrm{Cl}$ & - & {$[59-71]$} & [12-19] & [9-18] & {$[3-11]$} \\
\hline$I^{2}$ Statistic & - & $73 \%$ & $49 \%$ & $74 \%$ & $81 \%$ \\
\hline$p$ value & - & 0.0001 & 0.0381 & $<0.0001$ & $<0.0001$ \\
\hline
\end{tabular}


reported by Johnston et al., results were similar for treatment default (15\% [95\% CI 12-19] versus 13\% [95\% CI 9-17]), death (13\% [95\% CI 9-18] versus $11 \%$ [95\% CI 9-13]) and treatment failure (6\% [95\% CI 3-11] versus 8\% [95\% CI 5-11]) [12].

The success of cb-DOTS programs for treatment of drug-susceptible TB has been the subject of a previous systematic review. Kangovi et al. evaluated 24 programs and reported an overall treatment success rate of $80 \cdot 1 \%$ [95\% CI 77.1-83.2\%] [27]. Their definition for communitybased therapy included DOT by a community member 'in a location other than a health facility or TB club'. Our inclusion criteria were less rigid and included programs that delivered medication from health care facilities when associated with a form of community support.

More recently, a systematic review by Bassili et al. examined outcomes in ambulatory MDRTB treatment programs, comparing outcomes to those from hospital-based programs [28]. Outcomes were similar between ambulatory and hospital-based outcomes. Studies included for review did not maintain a requirement for community support. Related to inclusion/exclusion criteria, this study included only 8 studies in the ambulatory care arm, and did not include large cohorts by Mitnick, Tupasi, Singla $[16,21,23]$. In addition, two treatment cohorts, including the largest analyzed, were from high income countries $[29,30]$. Thus, findings from this review may not necessarily reflect the majority of community-based MDR-TB management.

\section{Study limitations}

The programs analyzed in this review varied in terms of DOT delivery site and community support. DOT sites included hospitals, clinics, community health centres and patient homes. Meanwhile, community support varied, and included intense educational sessions for patients and families, working with a nominated community support person, food supplementation, and transportation support. DOTS delivery was provided by various groups, including nurses, health care workers (HCWs), community members, and family members. The variability in community delivery and community supports makes the evaluation 
Table 4 Treatment success among study subgroups

\begin{tabular}{|c|c|c|}
\hline Subgroups & $\begin{array}{l}\text { Studies } \\
\text { (n) }\end{array}$ & $\begin{array}{l}\text { Treatment success } \\
\qquad(95 \% \mathrm{Cl})\end{array}$ \\
\hline \multicolumn{3}{|l|}{ Year study began } \\
\hline 2002 or later & 5 & $68 \%(59-75)$ \\
\hline Before 2002 & 5 & $63 \%(52-73)$ \\
\hline \multicolumn{3}{|l|}{ Patient's age } \\
\hline Included patients $\leq 14$ years old & 6 & $67 \%(54-78)$ \\
\hline All patients $>14$ years old & 4 & $65 \%(62-68)$ \\
\hline \multicolumn{3}{|l|}{ HIV prevalence } \\
\hline $0-2 \%$ & 4 & $72 \%(61-81)$ \\
\hline $\mathrm{HIV}>2 \%$ & 2 & $85 \%(55-100)$ \\
\hline Not specified or unknown & 4 & $61 \%(46-75)$ \\
\hline \multicolumn{3}{|l|}{ XDRTB prevalence } \\
\hline $0 \%$ & 3 & $75 \%(55-91)$ \\
\hline$>0 \%$ & 2 & $53 \%(26-78)$ \\
\hline Not specified or unknown & 5 & $67 \%(61-73)$ \\
\hline \multicolumn{3}{|l|}{ Treatment model } \\
\hline Individualized & 6 & $65 \%(54-75)$ \\
\hline Standardized & 4 & $66 \%(60-71)$ \\
\hline \multicolumn{3}{|l|}{ DOTS location } \\
\hline Included home-based option & 4 & $64 \%(61-68)$ \\
\hline Clinic or public health centre only & 4 & $63 \%(45-79)$ \\
\hline Not specified & 2 & $82 \%(54-98)$ \\
\hline \multicolumn{3}{|l|}{ DOTS provider } \\
\hline $\begin{array}{l}\text { Family members, neighbours or } \\
\text { household members sometimes utilized }\end{array}$ & 3 & $62 \%(55-69)$ \\
\hline $\begin{array}{l}\text { Only } \mathrm{CHWs}, \mathrm{HCW} \text { and other } \\
\text { medical practitioners }\end{array}$ & 7 & $66 \%(57-74)$ \\
\hline
\end{tabular}

and comparison of individual community programs difficult. However, this variability likely stems from the community-responsive design of such programs, and is likely essential for the success of cb-MDRTB programs. We attempted to identify elements of cb-MDRTB programs associated with improved outcomes, such as DOTS location or DOTS provider. Based on this analysis, however, there were no significant associations with improved treatment outcomes, possibly related to the limited sample size.

The community impact of cb-MDRTB was difficult to capture in this study. We captured individual patient outcomes associated with cb-MDRTB programs, but the effect of cb-MDRTB on treatment wait times, community and hospital MDRTB transmission, community engagement and stigma, and overall cost were not analyzed. These outcomes, however, are beginning to emerge in the MDRTB literature. For example, in South Africa, Heller et al. reported decreased waiting times in cb-MDRTB when compared to a traditional, hospital based program [31]. Meanwhile, Fitzpatrick and Floyd examined costeffectiveness of four MDRTB treatment programs and found that the cost per DALY averted favours cbMDRTB therapy [32]. Further assessments will be required to better understand the influence of cb-MDRTB programs on transmission dynamics, community perception, and other population-based aspects of TB control. In addition, the stability of cb-MDRTB treatment programs during rapid scale-up will also be an important issue given the recent expansion in MDRTB point of care diagnostic capacity [33].

We should emphasize that up to four studies from our analysis were included in previous systematic reviews, which partially accounts for their similar outcomes. These four studies, however, contribute to less than $20 \%$ of the outcomes reported in all previous analyses. We considered comparing cb-MDRTB studies to studies reporting on other types of treatment programs. Unfortunately, treatment protocols are not well-described in most studies, preventing strict classification and comparison between treatment programs. In addition, our inclusion of more recent publications may bias our results towards improved MDRTB outcomes in this cohort. Indeed, our subgroup analysis demonstrates nonsignificant improvement in treatment outcomes between studies starting before and after 2002. However, the five studies published in or after 2009 did not demonstrate significant differences in outcomes (data not shown). Lastly, we were limited by the number of studies available for analysis; with only ten studies and 1288 patients available for comparison, subgroup analysis was quite limited.

\section{Conclusion}

In conclusion, this systematic review and meta-analysis of cb-DRTB therapy demonstrates that the published results of community-based MDRTB and XDRTB treatment programs appear to have adequate treatment outcomes. These results help strengthen the evidence base to support the WHO's conditional recommendation for cb-MDRTB therapy and support recent calls for decentralized MDRTB care [34]. More research is required to examine individual and population-based effects of cb-MDRTB care: How do outcomes from home-based care compare with clinic-based ambulatory care? What community supports are essential to maintaining adherence and successful outcomes in financially strapped MDRTB treatment programs? What aspects of MDRTB diagnosis and treatment can a national TB treatment program safely decentralize? On a population level the effect of community engagement and education should be analyzed more closely, along with careful epidemiological study on MDRTB transmission. In our opinion, the call for 
decentralized MDRTB treatment requires a rapid but well-considered response.

\section{Additional files}

\section{Additional file 1: Prisma 2009 checklist. \\ Additional file 2: Funnel Plot with pseudo 95\% confidence intervals. Additional file 3: Univariate meta-regression of DRTB treatment success.}

\section{Competing interests}

The authors declare that they have no competing interests.

\section{Authors' contributions}

PW contributed to study design, data acquisition, data analysis, manuscript preparation and editing. WC contributed to study design, data analysis, manuscript preparation and editing. VC contributed to study design, manuscript preparation and editing. JJ contributed to study design, data acquisition, data analysis, manuscript preparation and editing. All authors read and approved the final manuscript.

\section{Author details}

${ }^{1}$ School of Humanitarian Studies, Royal Roads University, 2005 Sooke Rd, Victoria, British Columbia. ${ }^{2}$ Collaboration for Outcomes Research and Evaluation, University of British Columbia, 2405 Wesbrook Mall, Vancouver, Canada. ${ }^{3}$ Division of Respirology, University of British Columbia, Vancouver, Canada. ${ }^{4}$ The British Columbia Center for Disease Control, 655 West 12th Avenue, Vancouver, BC V5Z4R4, Canada.

\section{Received: 4 September 2013 Accepted: 28 May 2014}

Published: 17 June 2014

\section{References}

1. Gandhi NR, Nunn P, Dheda K, Schaaf HS, Zignol M, van Soolingen D, Jensen $\mathrm{P}$, Bayona J: Multidrug-resistant and extensively drug-resistant tuberculosis: a threat to global control of tuberculosis. Lancet 2010, 375(9728):1830-1843.

2. World Health Organization: Global Tuberculosis Report. Geneva: WHO; 2012.

3. Jacobson KR, Tierney DB, Jeon CY, Mitnick CD, Murray MB: Treatment outcomes among patients with extensively drug-resistant tuberculosis: systematic review and meta-analysis. Clin Infect Dis 2010, 51(1):6-14.

4. World Health Organization: Global Plan to Stop TB 2011-2015. Geneva: WHO; 2011.

5. Laserson KF, Thorpe LE, Leimane V, Weyer K, Mitnick CD, Riekstina V, Zarovska E, Rich ML, Fraser HS, Alarcon E, Cegielski JP, Grzemska M, Gupta R, Espinal M: Speaking the same language: treatment outcome definitions for multidrug-resistant tuberculosis. Int J Tuberc Lung Dis 2005, 9(6):640-645.

6. WHO: Guidelines for Programmatic Management of Drug-Resistant Tuberculosis (2011 Update). Geneva: WHO; 2011

7. Burgos M, Gonzalez LC, Paz EA, Gournis E, Kawamura LM, Schecter G, Hopewell PC, Daley CL: Treatment of multidrug-resistant tuberculosis in San Francisco: an outpatient-based approach. Clin Infect Dis 2005, 40(7):968-975

8. Seung KJ, Omatayo DB, Keshavjee S, Furin JJ, Farmer PE, Satti H: Early outcomes of MDR-TB treatment in a high HIV-prevalence setting in Southern Africa. PLoS One 2009, 4(9):e7186.

9. Adatu F, Odeke R, Mugenyi M, Gargioni G, McCray E, Schneider E, Maher D: Implementation of the DOTS strategy for tuberculosis control in rural Kiboga District, Uganda, offering patients the option of treatment supervision in the community, 1998-1999. Int J Tuberc Lung Dis 2003, 7(9 Suppl 1):S63-71.

10. Okello D, Floyd K, Adatu F, Odeke R, Gargioni G: Cost and cost-effectiveness of community-based care for tuberculosis patients in rural Uganda. Int $J$ Tuberc Lung Dis 2003, 7(9 Suppl 1):S72-79.

11. Wandwalo E, Kapalata N, Egwaga S, Morkve O: Effectiveness of community-based directly observed treatment for tuberculosis in an urban setting in Tanzania: a randomised controlled trial. Int J Tuberc Lung Dis 2004, 8(10):1248-1254.

12. Johnston JC, Shahidi NC, Sadatsafavi M, Fitzgerald JM: Treatment outcomes of multidrug-resistant tuberculosis: a systematic review and meta-analysis. PLoS One 2009, 4(9):e6914.

13. Orenstein EW, Basu S, Shah NS, Andrews JR, Friedland GH, Moll AP, Gandhi NR, Galvani AP: Treatment outcomes among patients with multidrug-resistant tuberculosis: systematic review and meta-analysis. Lancet Infect Dis 2009, 9(3):153-161.

14. World Health Organization: Guidelines for the Programmatic Management of Drug-Resistant Tuberculosis Emergency Update 2008. Geneva: WHO; 2008.

15. Cox D: Analysis of Binary Data. London: Methuen; 1970.

16. Singla R, Sarin R, Khalid UK, Mathuria K, Singla N, Jaiswal A, Puri MM, Visalakshi P, Behera D: Seven-year DOTS-Plus pilot experience in India: results, constraints and issues. Int J Tuberc Lung Dis 2009, 13(8):976-981.

17. Joseph P, Desai VB, Mohan NS, Fredrick JS, Ramachandran R, Raman B, Wares F, Thomas A: Outcome of standardized treatment for patients with MDR-TB from Tamil Nadu, India. Indian J Med Res 2011, 133:529-534.

18. Thomas A, Ramachandran R, Rehaman F, Jaggarajamma K, Santha T, Selvakumar N, Krishnan N, Mohan NS, Sundaram V, Wares F, Narayanan PR: Management of multi drug resistance tuberculosis in the field: Tuberculosis Research Centre experience. Indian J Tuberc 2007, 54(3):117-124

19. Drobac PC, Mukherjee JS, Joseph JK, Mitnick C, Furin JJ, del Castillo H, Shin SS, Becerra MC: Community-based therapy for children with multidrug-resistant tuberculosis. Pediatrics 2006, 117(6):2022-2029.

20. Mitnick C, Bayona J, Palacios E, Shin S, Furin J, Alcantara F, Sanchez E, Sarria M, Becerra M, Fawzi MC, Kapiga S, Neuberg D, Maguire JH, Kim JY, Farmer P: Community-based therapy for multidrug-resistant tuberculosis in Lima, Peru. N Engl J Med 2003, 348(2):119-128.

21. Mitnick CD, Shin SS, Seung KJ, Rich ML, Atwood SS, Furin JJ, Fitzmaurice GM, Alcantara Viru FA, Appleton SC, Bayona JN, Bonilla CA, Chalco K, Choi S, Franke MF, Fraser HS, Guerra D, Hurtado RM, Jazayeri D, Joseph K, Llaro K, Mestanza L, Mukherjee JS, Munoz M, Palacios E, Sanchez E, Sloutsky A, Becerra MC: Comprehensive treatment of extensively drug-resistant tuberculosis. N Engl J Med 2008, 359(6):563-574.

22. Malla P, Kanitz EE, Akhtar M, Falzon D, Feldmann K, Gunneberg C, Jha SS, Maharjan B, Prasai MK, Shrestha B, Verma SC, Zignol M: Ambulatory-based standardized therapy for multi-drug resistant tuberculosis: experience from Nepal, 2005-2006. PLoS One 2009, 4(12):e8313.

23. Tupasi TE, Gupta R, Quelapio MI, Orillaza RB, Mira NR, Mangubat NV, Belen V, Arnisto N, Macalintal L, Arabit M, Lagahid JY, Espinal M, Floyd K: Feasibility and cost-effectiveness of treating multidrug-resistant tuberculosis: a cohort study in the Philippines. PLoS Med 2006, 3(9):e352.

24. Oyieng'o DP, Gardner P, Kisang A, Diero G, Sitienei L, Carter JJ: Community-based treatment of multidrug-resistant tuberculosis: early experience and results from Western Kenya. Public Health Action 2012, 2(2):38-42.

25. Satti $H$, McLaughlin MM, Omotayo DB, Keshavjee S, Becerra MC, Mukherjee $J S$, Seung KJ: Outcomes of comprehensive care for children empirically treated for multidrug-resistant tuberculosis in a setting of high HIV prevalence. PLoS One 2012, 7(5):e37114.

26. Ahuja SD, Ashkin D, Avendano M, Banerjee R, Bauer M, Bayona JN, Becerra MC, Benedetti A, Burgos M, Centis R, Chan ED, Chiang CY, Coh H, D’Ambrosio L, DeRiemer K, Dung NH, Enarson D, Falzon D, Flanagan K, Flood J, Garcia-Garcia ML, Gandhi N, Granich RM, Hollm-Delgado MG, Holtz TH, Iseman MD, Jarlsberg LG, Keshavjee S, Kim HR, Koh WJ, et al: Multidrug resistant pulmonary tuberculosis treatment regimens and patient outcomes: an individual patient data meta-analysis of 9,153 patients. PLoS Med 2012, 9(8):e1001300.

27. Kangovi S, Mukherjee J, Bohmer R, Fitzmaurice G: A classification and meta-analysis of community-based directly observed therapy programs for tuberculosis treatment in developing countries. $J$ Community Health 2009, 34(6):506-513.

28. Bassili A, Fitzpatrick C, Qadeer E, Fatima R, Floyd K, Jaramillo E: A systematic review of the effectiveness of hospital- and ambulatory-based management of multidrug-resistant tuberculosis. AmJTrop Med Hyg 2013, 89(2):271-280

29. Kim HJ, Hong YP, Kim SJ, Lew WJ, Lee EG: Ambulatory treatment of multidrug-resistant pulmonary tuberculosis patients at a chest clinic. Int J Tuberc Lung Dis 2001, 5(12):1129-1136. 
30. Narita M, Alonso P, Lauzardo M, Hollender ES, Pitchenik AE, Ashkin D: Treatment experience of multidrug-resistant tuberculosis in Florida, 1994-1997. Chest 2001, 120(2):343-348.

31. Heller T, Lessells RJ, Wallrauch CG, Barnighausen T, Cooke GS, Mhlongo L, Master I, Newell ML: Community-based treatment for multidrug-resistant tuberculosis in rural KwaZulu-Natal, South Africa. Int I Tuberc Lung Dis 2010, 14(4):420-426.

32. Fitzpatrick C, Floyd $K$ : A systematic review of the cost and cost effectiveness of treatment for multidrug-resistant tuberculosis. PharmacoEconomics 2012, 30(1):63-80.

33. Meyer-Rath G, Schnippel K, Long L, MacLeod W, Sanne I, Stevens W, Pillay S, Pillay Y, Rosen S: The impact and cost of scaling up GeneXpert MTB/RIF in South Africa. PLoS One 2012, 7(5):e36966

34. Cox H, Ford N: Decentralisation of multidrug-resistant-tuberculosis care and management. Lancet Infect Dis 2013, 13(8):644-646.

doi:10.1186/1471-2334-14-333

Cite this article as: Weiss et al:: Treatment outcomes from communitybased drug resistant tuberculosis treatment programs: a systematic review and meta-analysis. BMC Infectious Diseases 2014 14:333.

\section{Submit your next manuscript to BioMed Central and take full advantage of:}

- Convenient online submission

- Thorough peer review

- No space constraints or color figure charges

- Immediate publication on acceptance

- Inclusion in PubMed, CAS, Scopus and Google Scholar

- Research which is freely available for redistribution 